\title{
Effects of applying amoxicillin in juvenile mice on enamel mineralization and the expression of kallikrein-related peptidase 4 and tight junction proteins in ameloblasts
}

\author{
JIANGHONG GAO ${ }^{1-3^{*}}$, XINMEI LI ${ }^{2,4^{*}}$, LIPING GAO ${ }^{2,5}$, HAIYAN CHEN $^{6}$, BASHAYER H. BARAS $^{7,8}$, \\ XIAOJING LIU ${ }^{2}$, HAO LIU $^{2}$, AYESHA RANA $^{2}$, MEILI GAO ${ }^{9}$ and JIANPING RUAN ${ }^{1-3}$
}

\begin{abstract}
${ }^{1}$ Key Laboratory of Shaanxi Province for Craniofacial Precision Medicine Research, ${ }^{2}$ Department of Preventive Dentistry,
${ }^{3}$ Clinical Research Center of Shaanxi Province for Dental and Maxillofacial Diseases, College of Stomatology,

Xi'an Jiaotong University, Xi'an, Shaanxi 710004; ${ }^{4}$ Department of Stomatology, Yan'an People's Hospital, Yan'an,

Shaanxi 716000; ${ }^{5}$ Department of Stomatology, Inner Mongolia People's Hospital, Huhhot, Inner Mongolia 010020;

${ }^{6}$ Core Research Laboratory, The Second Affiliated Hospital of Xi'an Jiaotong University, Xi'an, Shaanxi 710004, P.R. China;

${ }^{7}$ Department of Advanced Oral Sciences and Therapeutics, University of Maryland School of Dentistry, Baltimore,

MD 21201, USA; ${ }^{8}$ Department of Restorative Dental Science, College of Dentistry, King Saud University,

Riyadh 11545, Saudi Arabia; ${ }^{9}$ Department of Biological Science and Engineering, The Key Laboratory of

Biomedical Information Engineering of Ministry of Education, School of Life Science and Technology,

Xi'an Jiaotong University, Xi'an, Shaanxi 710049, P.R. China
\end{abstract}

Received November 3, 2019; Accepted April 7, 2020

DOI: $10.3892 /$ ijmm.2020.4598

\begin{abstract}
Amoxicillin is a common pediatric drug. However, to the best of our knowledge, the role of amoxicillin in enamel hypomineralization has not yet been fully elucidated. The aim of the present study was to assess the effects of amoxicillin on enamel mineralization, the morphology of ameloblasts, as well as the expression of kallikrein-related peptidase 4 (KLK4), and the tight junction proteins, claudin 1 (CLDN1), claudin 4 (CLDN4) and occludin (OCLN), in ameloblasts of juvenile mice. A total of 36 3-day-old Kunming mice were randomly divided into three groups. The mice were administered 0,50 or $100 \mathrm{mg} / \mathrm{kg}$ amoxicillin by intragastric administration for
\end{abstract}

Correspondence to: Professor Meili Gao, Department of Biological Science and Engineering, The Key Laboratory of Biomedical Information Engineering of Ministry of Education, School of Life Science and Technology, Xi'an Jiaotong University, 28 Xianning West Road, Xi'an, Shaanxi 710049, P.R. China

E-mail: gml.1369@mail.xjtu.edu.cn

Professor Jianping Ruan, Key Laboratory of Shaanxi Province for Craniofacial Precision Medicine Research, College of Stomatology, Xi'an Jiaotong University, 98 Xiwu Road, Xi'an, Shaanxi 710004, P.R. China

E-mail: ruanjp@mail.xjtu.edu.cn

*Contributed equally

Key words: amoxicillin, enamel hypomineralization, kallikreinrelated peptidase 4 , tight junction proteins
19 days. The surface morphology and calcium (Ca), phosphorous (P) and carbon contents of mandibular incisors and first molars were examined by scanning electron microscopy and energy dispersive X-ray spectroscopy. Histological changes in the ameloblasts of mandibular incisors were analyzed by hematoxylin and eosin staining. The KLK4, CLDN1, CLDN4 and OCLN expression levels of ameloblasts were observed by immunohistochemical staining. The incidence of white patches in the incisor was $100 \%$ in the $100 \mathrm{mg} / \mathrm{kg}$ amoxicillin-treated groups. A greater number of enamel defects were observed in the incisal/occlusal half of mandibular incisors/molars compared with in the cervical half in the amoxicillin-treated groups. Following phosphoric-acid treatment, the enamel rod and interrod were aligned in a disorderly manner in the amoxicillin-treated groups. Amoxicillin decreased the $\mathrm{Ca} / \mathrm{P}$ ratio in the enamel of mandibular incisors and molars. More intercellular spaces among maturation ameloblasts were observed in the amoxicillin-treated groups. Amoxicillin decreased KLK4 and CLDN1, CLDN4 and OCLN expression in mature ameloblasts. The administration of amoxicillin in juvenile mice induced enamel hypomineralization, and the effects of amoxicillin on enamel hypomineralization may be mediated via multiple pathways.

\section{Introduction}

Tooth enamel is a highly mineralized substance that acts as a barrier to protect teeth (1). Ameloblasts, which are epithelial cells, are responsible for amelogenesis (1). Secretory ameloblasts secrete matrix proteins to organize the entire enamel thickness with approximately $30-35 \%$ of the final mineral content (2). During the maturation stage of amelogenesis, 
kallikrein-related peptidase 4 (KLK4) is secreted to degrade enamel proteins. Proteins and water are removed and specific ions required for the concurrent accretion of mineral are deposited in the enamel until the mineral content is $>95 \%$ in fully formed enamel $(3,4)$.

Ameloblasts are attached to each other at their lateral membranes by a complex of intercellular junctions during amelogenesis (5). The most apical complex of the intercellular junctions is tight junctions (TJs) (5). TJs generate the permeability barrier among neighboring cells and control the flux of ions and non-electrolytes through the paracellular space (5-8). In addition, TJs can also act as a 'fence' and permit cells to act in a polarized manner, which is crucial for morphogenesis, protein-membrane trafficking and transportation (5-8). The TJs of ameloblasts ensure a suitable microenvironment for enamel deposition and maturation by determining the paracellular permeability and selectivity of solutes $(5,9)$. Claudins (CLDNs) and occludin (OCLN) are integral membrane proteins of TJ strands (9). CLDN1, CLDN4 and OCLN are expressed in mature ameloblasts. These proteins may differentially regulate paracellular permeability against the enamel surface to perform their functions appropriately (9-13).

Amelogenesis is strictly controlled by genes. However, if enamel organ cells are exposed to environmental stress for a long period of time during critical periods of amelogenesis, enamel defects may occur, such as amelogenesis imperfecta, dental fluorosis, enamel hypoplasia and molar incisor hypomineralization (MIH) (14-16). Enamel hypomineralization poses an increased risk for toothaches, caries and concerns about appearance (17-19). Therefore, it is crucial to prevent enamel hypomineralization.

The $\beta$-lactam antibiotic, amoxicillin, is widely prescribed as a first-choice antibiotic for common infections in pediatrics and pedodontics, such as ear, nose and throat infections, pneumonia and other infections (20). However, certain studies have found that amoxicillin may affect enamel mineralization (21-27). Epidemiological studies have demonstrated that amoxicillin administration during pregnancy and/or early childhood may be associated with MIH (21-23). Furthermore, hypomineralization in enamel has been found in the offspring of pregnant rats administered amoxicillin daily (24). In addition, amoxicillin can play a contributing role in the development of tooth fluorosis (25). It has been reported that amoxicillin administered to 20- to 24-month-old children increases the risk of dental fluorosis (26), and an in vitro study further suggested that amoxicillin and fluoride exert a potentiation effect on the developing enamel of mouse molars (27). However, the pathological mechanisms underlying the effects of amoxicillin on enamel hypomineralization have not yet been fully elucidated. Furthermore, to the best of our knowledge, no in vivo studies using laboratory juvenile animals exposed to amoxicillin, which is similar to amoxicillin used in early childhood, have been performed to date. Therefore, the aim of the present study was to assess the effects in juvenile mice produced by amoxicillin administration on enamel mineralization, the morphology of ameloblasts and the expression of KLK4 and TJ proteins, including CLDN1, CLDN4 and OCLN. The findings of the present study may promote the understanding of the role of amoxicillin in enamel hypomineralization and the pathological mechanisms of enamel hypomineralization.

\section{Materials and methods}

Animals. A total of 6 female Kunming mice on gestation day 18 with a body weight of $40 \pm 3 \mathrm{~g}$ were purchased from the Experimental Animal Center of Xi'an Jiaotong University. The research was conducted in accordance with the Declaration of Helsinki and with the Guide for Care and Use of Laboratory Animals as adopted and promulgated by the United National Institutes of Health. All experimental protocols were approved by the Ethics Committee for the Use of Human or Animal Subjects of Xi'an Jiaotong University. Mice were kept in cages at room temperature and were provided ad libitum access to food and water. The temperature of the environment was maintained at $25 \pm 3^{\circ} \mathrm{C}$, with the relative humidity maintained at $40-60 \%$. Artificial lighting was provided for $12 \mathrm{~h}$ each day. The water, food and padding were changed every $24 \mathrm{~h}$.

After birth, the mouse offspring were raised with their mothers until they were weaned. A total of 6 mice from each mother, resulting in a total of 36 offspring mice, were randomly selected and divided into the 0,50 and $100 \mathrm{mg} / \mathrm{kg}$ amoxicillin treatment groups. Each group included 12 offspring mice, which were labeled on their back. Since day 3 after birth, the offspring mice in the control group were intragastrically administered saline at 8 a.m. and 8 p.m, and offspring in the experimental groups were also intragastrically administered amoxicillin at 50 or $100 \mathrm{mg} / \mathrm{kg}$ twice a day, at 8 a.m. and 8 p.m. Saline and amoxicillin treatment were administered for 19 days. The mother mice were fed a regular diet. The offspring mice were weighed daily and were weaned on day 21 after birth. On postnatal day 25 , all of the offspring mice were anesthetized by an intraperitoneal injection of $10 \%$ chloral hydrate at a dose of $400 \mathrm{mg}$ chloral hydrate per $\mathrm{kg}$ of animal body weight (28). No sign of peritonitis was observed following the intraperitoneal injection. The incisors of the mice were photographed with a digital camera (Canon; EOS M5) under natural light. The offspring were then sacrificed by cervical dislocation for the following experiment. On the same day the mother mice were administered an intraperitoneal injection of $10 \%$ chloral hydrate at a dose of $400 \mathrm{mg}$ chloral hydrate per kg of animal body weight, and no signs of peritonitis were observed after intraperitoneal injection. The mice were then sacrificed by cervical dislocation and handled according to the Ethics Committee for the Use of Human or Animal Subjects of Xi'an Jiaotong University. Direct cardiac palpation was used to confirm the death of mice.

Tissue preparation. Complete mandibles were harvested and the surrounding tissues of the bone were gently removed. A total of 12 right hemimandibles in each group were washed with distilled water and fixed for $24 \mathrm{~h}$ in $5 \%$ glutaraldehyde at room temperature prior to performing scanning electron microscopy (SEM) and energy dispersive X-ray spectroscopy (EDX) analysis. Subsequently, 6 of the 12 left hemimandibles in each group, which were randomly selected, were immersed in $1 \%$ phosphoric-acid for $60 \mathrm{sec}$, and were then washed with distilled water three times. In order to perform histological and immunohistochemistry analyses, the other 6 left hemimandibles in each group were washed with $0.01 \%$ phosphate-buffered saline (PBS) solution and were then fixed by immersion in 5\% paraformaldehyde in $0.1 \mathrm{M}$ phosphate buffer $(\mathrm{pH} 7.3)$ for $48 \mathrm{~h}$ 
at room temperature. Hemimandibles were then decalcified in $10 \%$ EDTA ( $\mathrm{pH} \mathrm{7.3)} \mathrm{for} 4$ weeks at $4^{\circ} \mathrm{C}$ and embedded in paraffin. Sagittal serial sections at a thickness of 5-10 $\mu \mathrm{m}$ were prepared and mounted on polyline-coated glass slides.

SEM and EDX analyses. For both SEM and EDX analyses, the incisal/occlusal half and cervical half of labial/facial surface enamel of the mandibular incisors and the molars were assessed, respectively. For the mandibular incisors treated by $1 \%$ phosphoric-acid, the incisal half of distal surface enamel of the mandibular incisors were assessed. The outer enamel structure of each hemimandible was examined by SEM (JXA-8100; JEOL, Ltd.) operating in low-vacuum mode for secondary electron imaging. The JXA-8100 SEM was equipped with an EDX system (INCA Energy; Oxford Instruments) for qualitative and quantitative analyses and elemental mapping. Each sample without phosphoric-acid was randomly observed at three points in each half of enamel (incisal/occlusal half and cervical half of labial/facial enamel). Each sample with phosphoric-acid was randomly observed at three points in each incisal half of labial enamel. A total of 6 micrographs of each sample without phosphoric-acid and 3 micrographs of each sample with phosphoric-acid were obtained at each magnification. The images were compared among the groups and representative images were selected. The relative amounts of calcium $(\mathrm{Ca})$, phosphorus $(\mathrm{P})$ and carbon (C) of samples without phosphoric-acid were assessed as atom percentage (Atom\%) by EDX analysis, and the mean Atom $\%$ of $\mathrm{Ca}, \mathrm{P}, \mathrm{C}$ and $\mathrm{Ca} / \mathrm{P}$ ratios of each group was calculated.

Histological analysis. Deparaffinized sections were stained using the haematoxylin and eosin staining technique. Briefly, the slides were immersed in haematoxylin for $5 \mathrm{~min}$ and then washed. Then the slides were stained with $1 \%$ eosin for $3 \mathrm{~min}$ and washed in tap water. The slides were dehydrated in $95 \%$ alcohol and $100 \%$ alcohol in turn. The slides were cleared with xylene twice. Qualitative histology was performed on the stained sections using a light microscope Leica DM 750 (Leica Microsystems $\mathrm{GmbH}$ ) with an attached digital camera Leica ICC50 HD (Leica Microsystems GmbH) at x200 magnification.

Immunohistochemistry. Immunohistochemical staining was performed on arrayed tissue samples according to a previously described protocol (29). Briefly, dewaxed sections were rinsed in PBS and subjected to antigen retrieval in $10 \mathrm{mM}$ citrate buffer ( $\mathrm{pH} \mathrm{6.0)}$ for $20 \mathrm{~min}$ at $95^{\circ} \mathrm{C}$ in a microwave oven. Subsequently, endogenous peroxidase was blocked with $3 \% \mathrm{H}_{2} \mathrm{O}_{2}$ for $10 \mathrm{~min}$, and the sections were then washed with PBS three times. Non-specific staining was blocked for 30 min at $37^{\circ} \mathrm{C}$ with rabbit serum (cat. no. ab7487; Abcam) in a wet box, followed by overnight incubation at $4^{\circ} \mathrm{C}$ with rabbit anti-KLK4 (1:100; cat. no. Ab197657; Abcam), CLDN1 (1:100; cat. no. 13050-1-AP; Proteintech Group, Inc.), CLDN4 (1:200; cat. no. 16195-1-AP; Proteintech Group, Inc.) and OCLN (1:100; cat. no. 13409-1-AP; Proteintech Group, Inc.) antibodies, and non-immune IgG (1:200; cat. no. ab37415; Abcam) served as a negative control. Following incubation with primary antibodies, the slides were washed in
PBS three times and antibody binding was visualized using the Vectastain ABC Elite kit (cat. no. PK-6100; Vector Laboratories, Inc). The slides were then washed with PBS solution. This was followed by incubation with biotinylated anti-goat IgG (1:200; cat. no. PK-6100; Vector Laboratories, Inc.) for $15 \mathrm{~min}$ at $37^{\circ} \mathrm{C}$. The reaction was amplified with Ultra-Steptavidin conjugated to horseradish peroxidase (1:50; cat. no. PK-6100; Vector Laboratories, Inc.) and visualized with diaminobenzidine. Slides were counterstained with hematoxylin for $3 \mathrm{~min}$ at room temperature prior to microscopic analysis. Immunohistochemical images were acquired using a Leica DM 750 microscope (Leica Microsystems $\mathrm{GmbH}$ ) with an attached digital camera Leica ICC50 HD (Leica Microsystems GmbH) a x200 magnification.

Quantification of staining. Following immunohistochemistry staining, quantitative immunostaining was assessed as previously described (30). The positive immunostaining expression of KLK4, CLDN1, CLDN4 and OCLN in mature ameloblasts of mandibular incisors was subjected to microscopic analysis. The intensity of the staining signal was measured and documented using Image-Pro Plus 6.0 image analysis software (Media Cybernetics, Inc.). The intensity of staining was expressed as the mean signal density of tissue areas from six randomly selected visions. The mean signal densities were made relative to the mean signal density of the $0 \mathrm{mg} / \mathrm{kg}$ amoxicillin-treated group.

Statistical analysis. All assays were conducted with three independent experiments by SPSS 17.0 software (SPSS, Inc.). Data are expressed as the mean \pm standard deviation. One-way analysis of variance followed by Tukey's method was used to compare differences between groups. $\mathrm{P}<0.05$ was considered to indicate a statistically significant difference.

\section{Results}

Amoxicillin has no effect on body weight and induces chalk/white patches on the incisor enamel of juvenile mice. There was no significant difference in the body weight of the juvenile mice between the control and amoxicillin-exposed groups from the 3 rd day to the 25 th day ( $P>0.05$; Fig. 1A). However, the color and translucency of incisor enamel was altered following amoxicillin exposure (Fig. 1B). In the control group, the enamel of maxillary and mandibular incisors was orange in color, and smooth and translucent (Fig. 1B). However, chalk/white patches in the incisor enamel, particularly the incisal half, were observed in the amoxicillin-exposed groups (Fig. 1B). Furthermore, 8.3, 58 and $100 \%$ of mice exhibited enamel chalk/white patches in the 0,50 and $100 \mathrm{mg} / \mathrm{kg}$ amoxicillin-exposed groups, respectively.

Amoxicillin induces enamel hypomineralization of incisors and molars of juvenile mice. The SEM observations revealed that the enamel surface of the incisors (Fig. 2A and D) and molars (Fig. 3A and D) was smooth and homogeneous with a few visible cracks in the control group. However, the incisal half of the mandibular incisors exhibited a rough, irregular and scratched enamel pattern in the $50 \mathrm{mg} / \mathrm{kg}$ amoxicillin-exposed group (Fig. 2B). Deeper scratched enamel defects and foam-like 
A

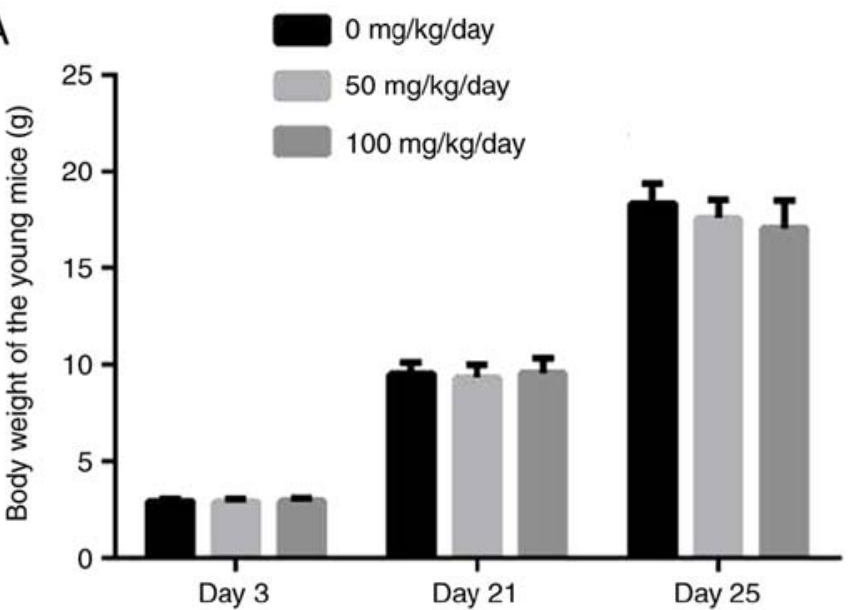

B

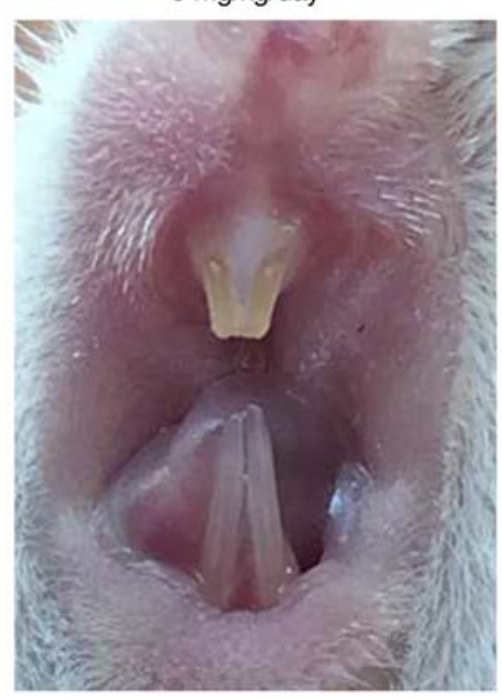

$50 \mathrm{mg} / \mathrm{kg} / \mathrm{day}$

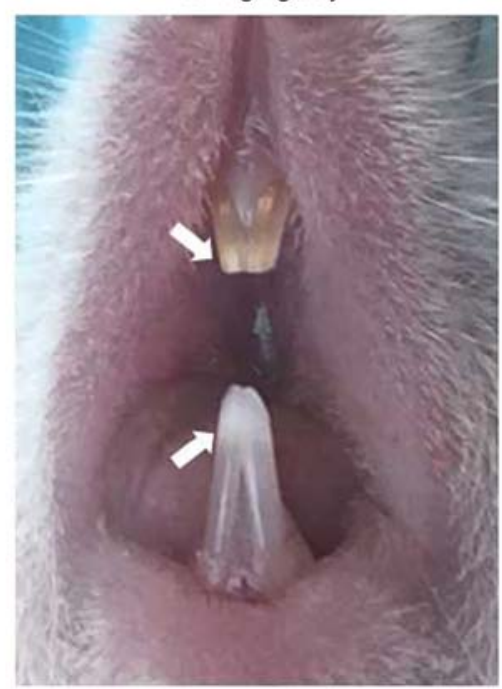

$100 \mathrm{mg} / \mathrm{kg} /$ day

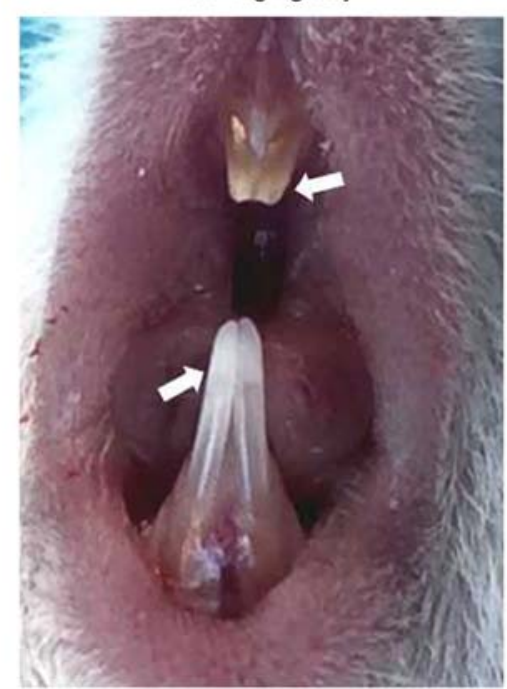

Figure 1. Effects of amoxicillin on body weight and morphology of the incisors in young mice. (A) Weight changes, data are presented as mean \pm standard deviation. (B) Representative photographs of the mice incisors in the 0,50 and $100 \mathrm{mg} / \mathrm{kg} / \mathrm{day}$ amoxicillin-exposed groups, respectively. Arrows indicate chalk/white patches in the enamel of the maxillary and mandibular incisors.

enamel with obvious holes were observed in the $100 \mathrm{mg} / \mathrm{kg}$ amoxicillin-exposed group. The length of enamel defect could be extended to several microns (Fig. 2C). However, there were no obvious enamel defects in the cervical half enamel of the mandibular incisors in the 50 (Fig. 2E) and $100 \mathrm{mg} / \mathrm{kg}$ (Fig. 2F) amoxicillin-exposed groups. Scratched enamel with a different depth was also often observed in the occlusal half of molars enamel in the 50 (Fig. 3B) and $100 \mathrm{mg} / \mathrm{kg}$ (Fig. 3C) amoxicillin-exposed groups; however, the enamel defects were not as severe as those in the incisal half enamel of the mandibular incisors. Similar to the mandibular incisors, enamel defects in the cervical half of the mandibular molars were not obvious in the 50 (Fig. 3E) and $100 \mathrm{mg} / \mathrm{kg}$ (Fig. 3F) amoxicillin-exposed groups.

Following phosphoric acid etching, the rods and interrod enamel were alternately arranged. The enamel rod was composed of hydroxyapatite crystals whose long axis runs mostly in the general direction of the longitudinal axis of the rod. The interrod surrounds each enamel rod, and its crystals are oriented in a direction different from those making up the rod. The packing of the crystals was tight and well organized in the control group (Fig. 4A). The borders between the enamel rods and inter-rods were indistinct and were hardly visible in some sites, where the packing of the crystals was less tight and less well organized in the 50 (Fig. 4B) and 100 (Fig. 4C) mg/kg amoxicillin-exposed groups.

EDX analysis revealed that, except for the $50 \mathrm{mg} / \mathrm{kg}$ amoxicillin-exposed group, amoxicillin significantly reduced the mean values of $\mathrm{Ca}, \mathrm{P}$ and the $\mathrm{Ca} / \mathrm{P}$ ratio of the incisal half (Fig. 5A and B) and cervical half (Fig. 5C and D) of mandibular incisor enamel $(\mathrm{P}<0.05)$, while the mean values of $\mathrm{C}$ were not evidently altered by amoxicillin $(\mathrm{P}>0.05)$. No significant differences were found for the changes in $\mathrm{Ca}, \mathrm{P}$ and $\mathrm{C}$ in the occlusal half (Fig. 5E and F) and cervical half (Fig. 5G and H) of the mandibular first molar enamel between the groups; whereas amoxicillin significantly decreased the $\mathrm{Ca} / \mathrm{P}$ ratio in the occlusal half $(\mathrm{P}<0.01$; Fig. $5 \mathrm{~F})$ and in the cervical half $(\mathrm{P}<0.05$; Fig. $5 \mathrm{H})$ enamel of mandibular first molar compared with the control group.

Amoxicillin induces space alterations among mature ameloblasts and cyst-like lesions in the incisors of the juvenile mice. Compared with the $0 \mathrm{mg} / \mathrm{kg}$ (Fig. 6A) amoxicillin-exposed group, intercellular spaces among secretory ameloblasts 

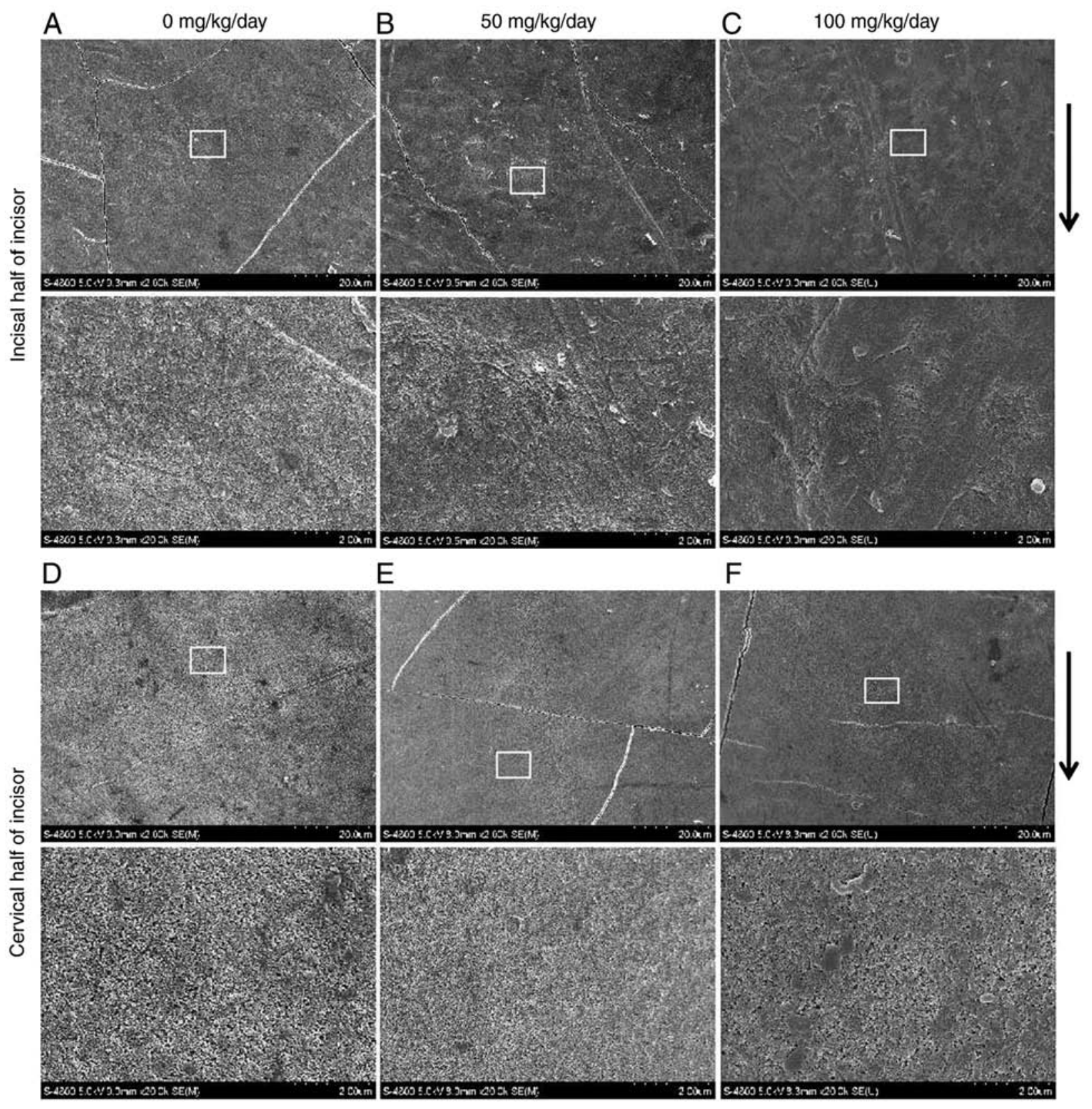

Figure 2. Effects of amoxicillin on the enamel surface of the mandibular incisors. Representative scanning electron microscopy micrographs of the enamel surface of the incisors. (A) The micrographs of the enamel surface of the incisors incisal half in the $0 \mathrm{mg} / \mathrm{kg} / \mathrm{day}$ amoxicillin-exposed group. (B) The micrographs of the enamel surface of the incisors incisal half in the $50 \mathrm{mg} / \mathrm{kg} /$ day amoxicillin-exposed group. (C) The micrographs of the enamel surface of the incisors incisal half in the $100 \mathrm{mg} / \mathrm{kg} /$ day amoxicillin-exposed group. (D) The micrographs of the enamel surface of the incisors cervical half in the $0 \mathrm{mg} / \mathrm{kg} / \mathrm{day}$ amoxicillin-exposed group. (E) The micrographs of the enamel surface of the incisors cervical half in the $50 \mathrm{mg} / \mathrm{kg} / \mathrm{day}$ amoxicillin-exposed group. (F) The micrographs of the enamel surface of the incisors cervical half in the $100 \mathrm{mg} / \mathrm{kg} / \mathrm{day}$ amoxicillin-exposed group. Scale bars, $20 \mu \mathrm{m}$ (upper images) and $2 \mu \mathrm{m}$ (lower images).

appeared to be similar in the 50 (Fig. 6B) and $100 \mathrm{mg} / \mathrm{kg}$ (Fig. 6C) amoxicillin-exposed groups. In the control group, the mature ameloblasts were orderly arranged and obvious gaps among the cells were occasionally observed (Fig. 6D). However, larger intercellular spaces among mature ameloblasts could be identified in the 50 (Fig. 6E) and $100 \mathrm{mg} / \mathrm{kg}$ (Fig. 6F) amoxicillin-treated groups. Furthermore, it was demonstrated that some mature ameloblasts separated from the enamel and formed vesicles in the amoxicillin-exposed groups (Fig. 6G). In total, $8.3,50$ and $75 \%$ of mouse samples exhibited vesicles in the 0,50 and $100 \mathrm{mg} / \mathrm{kg}$ amoxicillin-exposed groups, respectively.
Amoxicillin reduces the expression of KLK4, CLDN1, CLDN4 and OCLN in mature ameloblasts of juvenile mice. Immunohistochemical staining revealed that brown granules were found in the cytoplasm of dental epithelial cells of the maturation stage in the control group, particularly in mature ameloblasts (Fig. 7A). However, immunohistochemical staining of KLK4 in the 50 (Fig. 7B) and $100 \mathrm{mg} / \mathrm{kg}$ (Fig. 7C) amoxicillin-exposed groups exhibited a pale yellow color, which was lighter in color than that in the control group. Weak staining for CLDN1 (Fig. 7D) and OCLN (Fig. 7J) was detected at the distal ends of mature ameloblasts in the control group. The staining color of CLDN1 in the 50 (Fig. 7E) and 

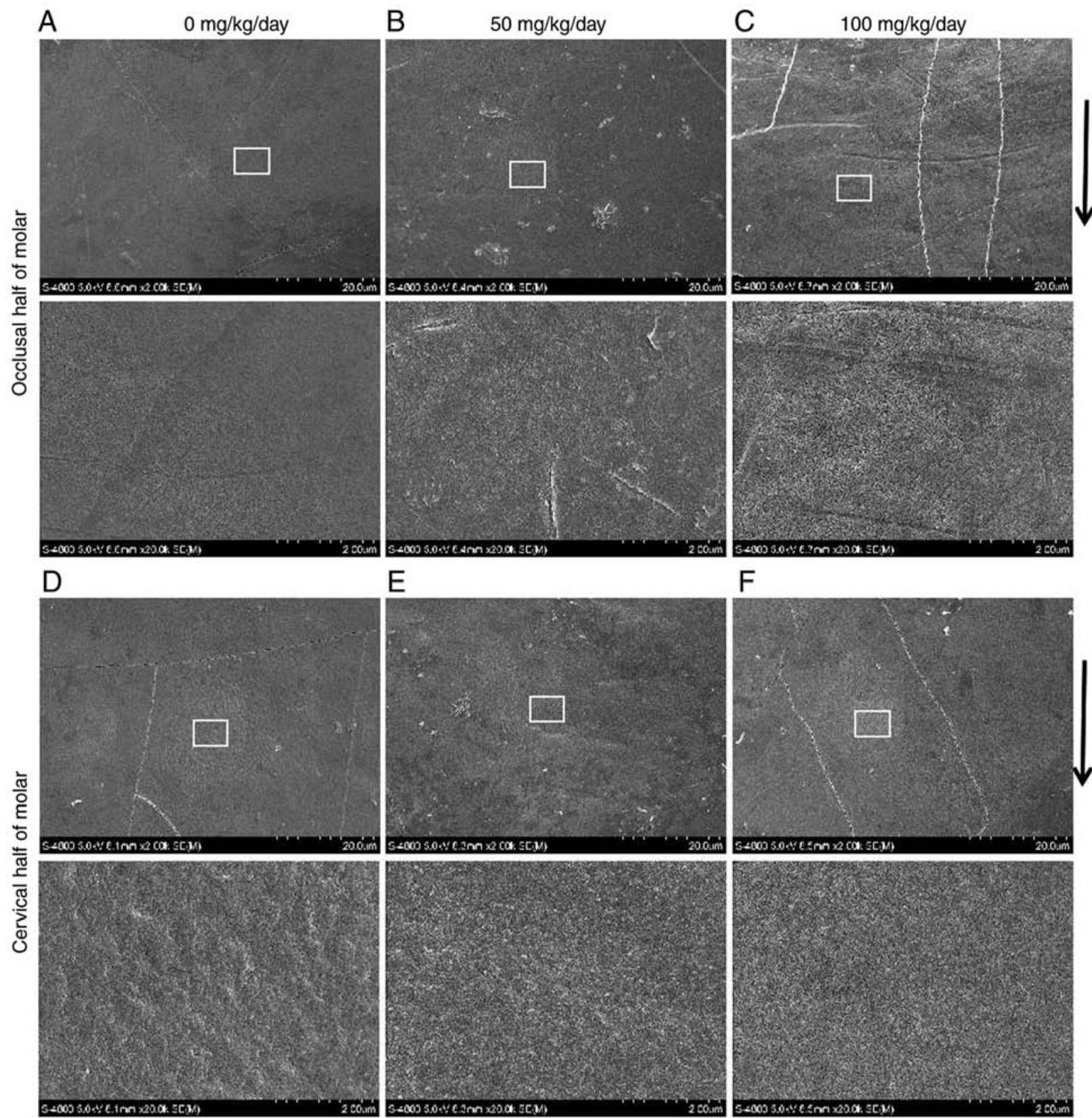

$\mathrm{E}$

$\mathrm{F}$
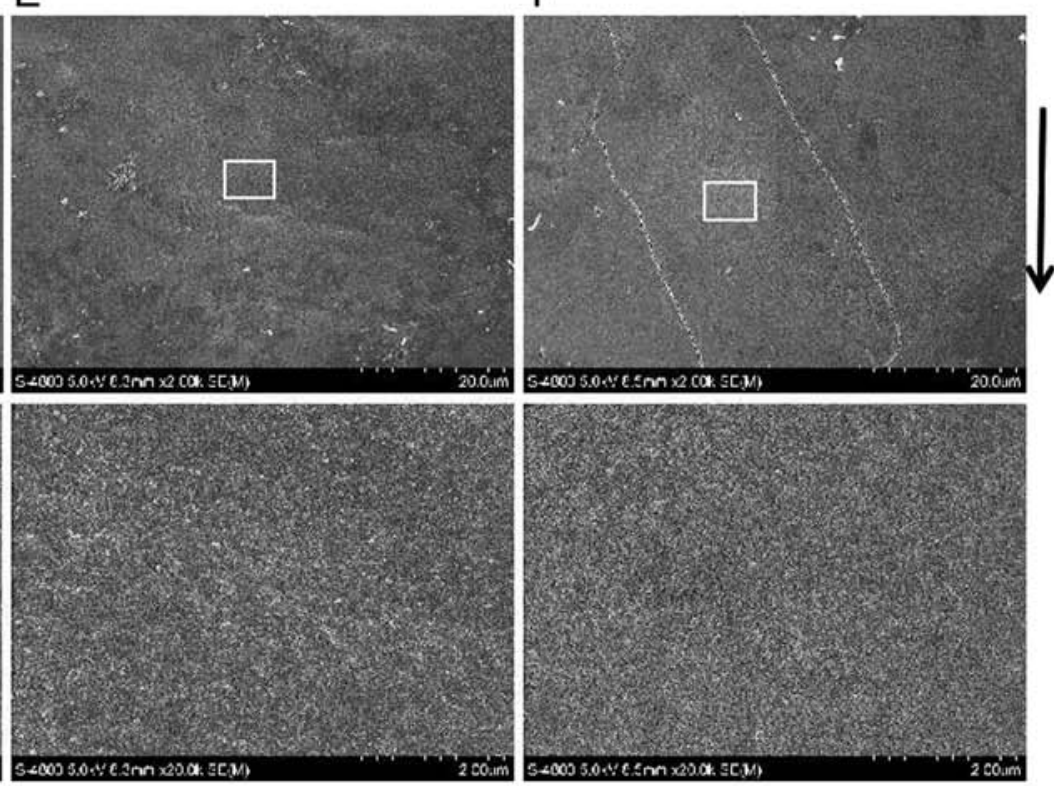

Figure 3. Effects of amoxicillin on the enamel surface of the mandibular molars. Representative scanning electron microscopy micrographs of the enamel surface of the mandibular first molars. (A) The micrographs of the enamel surface of the first molars occlusal half in the $0 \mathrm{mg} / \mathrm{kg} / \mathrm{day}$ amoxicillin-exposed group. (B) The micrographs of the enamel surface of the first molars occlusal half in the $50 \mathrm{mg} / \mathrm{kg} / \mathrm{day}$ amoxicillin-exposed group. (C) The micrographs of the enamel surface of the first molars occlusal half in the $100 \mathrm{mg} / \mathrm{kg} /$ day amoxicillin-exposed group. (D) The micrographs of the enamel surface of the first molars cervical half in $0 \mathrm{mg} / \mathrm{kg} / \mathrm{day}$ amoxicillin-exposed group. (E) The micrographs of the enamel surface of the first molars cervical half in the $50 \mathrm{mg} / \mathrm{kg} / \mathrm{day}$ amoxicillin-exposed group. (F) The micrographs of the enamel surface of the first molars cervical half in the $100 \mathrm{mg} / \mathrm{kg} / \mathrm{day}$ amoxicillin-exposed group. Scale bars, $20 \mu \mathrm{m}$ (upper images) and $2 \mu \mathrm{m}$ (lower images).

$100 \mathrm{mg} / \mathrm{kg}$ (Fig. 7F) amoxicillin-treated group became a little lighter. The staining color of OCLN in the 50 (Fig. 7K) and $100 \mathrm{mg} / \mathrm{kg}$ (Fig. 7L) amoxicillin-treated group appeared to be a little lighter. CLDN4 was detected at both ends of mature ameloblasts and other dental epithelial cells in the control group (Fig. 7G). The positive staining for CLDN4 in the dental epithelial cells was evidently lesser in the 50 (Fig. $7 \mathrm{H})$ and $100 \mathrm{mg} / \mathrm{kg}$ (Fig. 7I) amoxicillin-exposed groups as compared with the control group (Fig. 7G).

The quantification of staining revealed that the mean densities of KLK4-, CLDN1-, CLDN4- and OCLN-positive staining in mature ameloblasts in the 50 and $100 \mathrm{mg} / \mathrm{kg}$ groups were lower than that in the $0 \mathrm{mg} / \mathrm{kg}$ group, and the differences were statistically significant $(\mathrm{P}<0.05$; Fig. $7 \mathrm{M})$.

\section{Discussion}

Enamel hypomineralization is a qualitative developmental defect of enamel (14-16) and to the best of our knowledge, its etiology has not yet been fully determined. Amoxicillin used in early childhood may be associated with children's MIH, which is one type of enamel hypomineralization (21-23). Furthermore, amoxicillin use by children may increase the risk of dental fluorosis (25). In the present study, it was found 
A
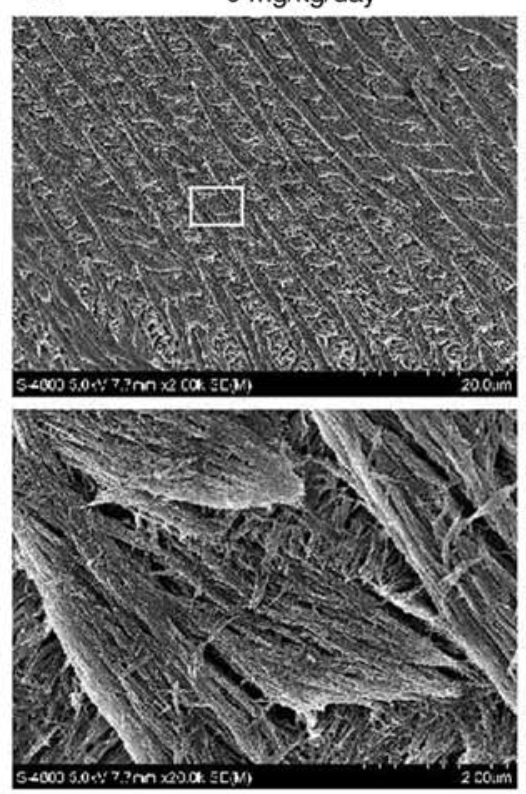

B
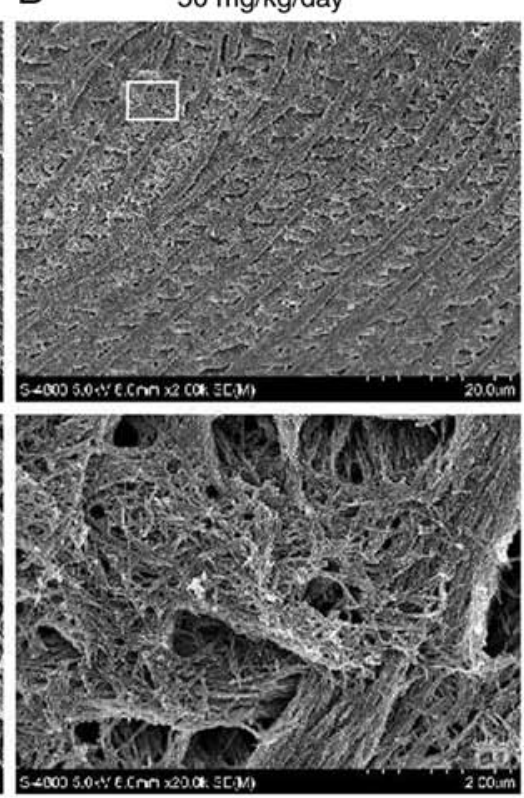

C $\quad 100 \mathrm{mg} / \mathrm{kg} / \mathrm{day}$
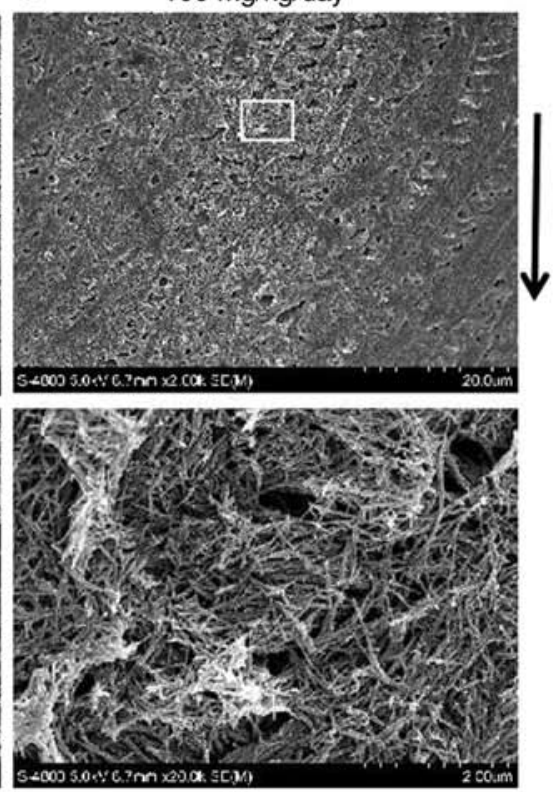

Figure 4. Effects of amoxicillin on the distal enamel surface of the lower incisors after 1\% phosphoric-acid treatment. Representative scanning electron microscopy micrographs of the distal enamel surface of the lower incisors. (A) The micrographs of the distal enamel surface of the incisors incisal half in $0 \mathrm{mg} / \mathrm{kg} /$ day amoxicillin-exposed group. (B) The micrographs of the distal enamel surface of the incisors incisal half in $50 \mathrm{mg} / \mathrm{kg} / \mathrm{day}$ amoxicillin-exposed group. (C) The micrographs of the distal enamel surface of the incisors incisal half in $100 \mathrm{mg} / \mathrm{kg} / \mathrm{day}$ amoxicillin-exposed group. Scale bars, $20 \mu \mathrm{m}$ (upper images) and $2 \mu \mathrm{m}$ (lower images).

that continuous amoxicillin administration (from postnatal days 3 to 21) led to enamel hypomineralization in juvenile mice. Furthermore, it was found that amoxicillin reduced the expression of KLK4, CLDN1, CLDN4 and OCLN in mature ameloblasts.

The first mandibular molars of 3-day-old Kunming mice begin to secrete enamel matrix proteins and they erupt approximately on postnatal day 20 (31). During postnatal days 3 to 21 , the first mandibular molars of Kunming mice experience both secretory and maturation periods of amelogenesis. Therefore, the young mice were exposed to amoxicillin from postnatal days 3 to 21 to intervene with the whole mineralization period of the first mandibular enamel.

The dosage of amoxicillin prescribed for children is $\geq 25 \mathrm{mg} / \mathrm{kg}(32,33)$. According to the guideline of drug conversion from humans to mice provided by the USA Food and Drug Administration, the dose of $25 \mathrm{mg} / \mathrm{kg}$ in humans is $~ 310 \mathrm{mg} / \mathrm{kg}$ in mice (34). However, some studies have demonstrated that pregnant rats and adult mice exposed to 50 and $100 \mathrm{mg} / \mathrm{kg}$ amoxicillin exhibit enamel defects $(24,35)$, which indicates that the enamel is quite sensitive to amoxicillin. Furthermore, in the present study, 3-day-old mice were exposed to amoxicillin; thus, the lower doses of 50 and $100 \mathrm{mg} / \mathrm{kg}$ amoxicillin were selected. In addition, 50 and $100 \mathrm{mg} / \mathrm{kg}$ amoxicillin did not affect the body weight of young mice, which suggested that 50 and $100 \mathrm{mg} / \mathrm{kg}$ amoxicillin per day may be relatively safe for the metabolism of the young body.

In the present study, the enamel chalk/white patches induced by amoxicillin were similar to the clinical manifestation of enamel hypomineralization (19). It has been reported that enamel chalk/white patches appear in the enamel of mandibular incisors of adult mice exposed to amoxicillin for 60 days, while no enamel patches are found in the maxillary incisors (35). However, in the present study, the enamel chalk/white patches were also observed in the enamel of maxillary incisors. Adult mice were used in the previous study, while the present study used juvenile mice whose drug metabolism was weaker than that of adult mice. Properties of light reflection and the transmission of enamel are dependent on its texture, the orientation of enamel rods and histological characteristics $(36,37)$. Therefore, chalk/white patches and a less translucent appearance in the enamel surface suggested that surface smoothness and/or histological characteristics of the enamel may be affected by amoxicillin. Furthermore, some enamel defects in the enamel surface were found by SEM, which confirms the aforementioned finding. During chewing of mice, the dentin of maxillary incisor contacts the enamel of mandibular incisors due to enamel formed only on the labial surface of the mice incisors (38). Therefore, the enamel of maxillary incisors bear less friction than that of mandibular incisors. That may be the reason why the enamel white patches in maxillary incisors appeared less severe than those in the mandibular incisors, even if they were similarly affected by amoxcillin.

In the present study, amoxicillin reduced the ratio of $\mathrm{Ca} / \mathrm{P}$ in the mandibular incisors and first molars, which suggested that amoxicillin indeed caused enamel hypomineralization, even where there was no obvious enamel chalk/white patches. However, of note, the SEM observations revealed more enamel defects in the incisal/occlusal half of the enamel surface in the amoxicillin-exposed groups, which was a confirmation of the change in enamel of adult mice in a previous study (35). This may be caused by the bite and frictional force during chewing. The buccal cusps of mandibular first molars occluded with opposing central fossa areas of maxillary first molars; Approximately incisal one third of labial surface of the 
A

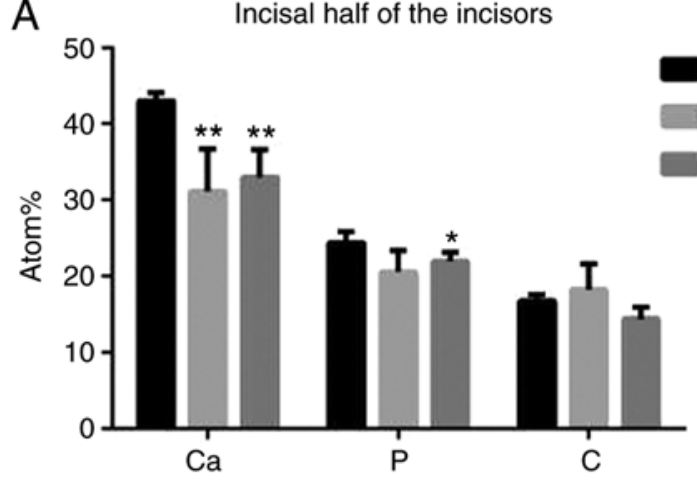

C Cervical half of the incisors

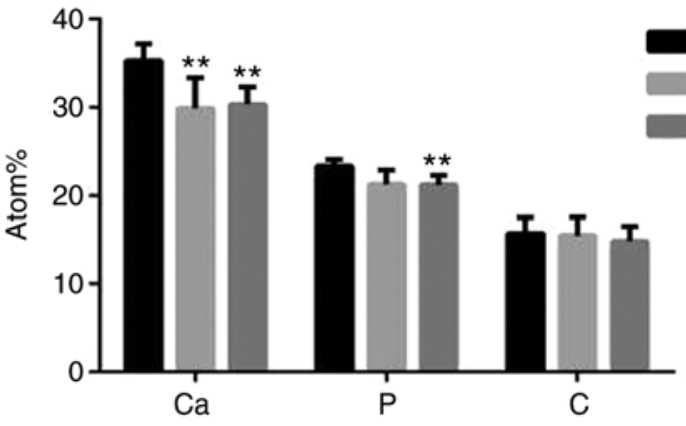

E

Occlusal half of the first molars

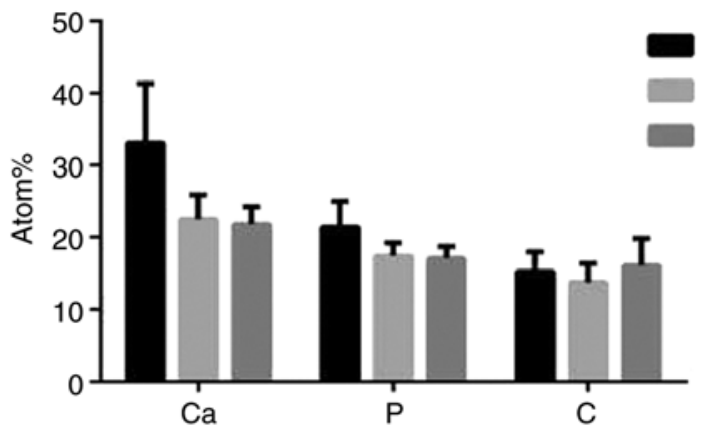

G Cervical half of the first molars

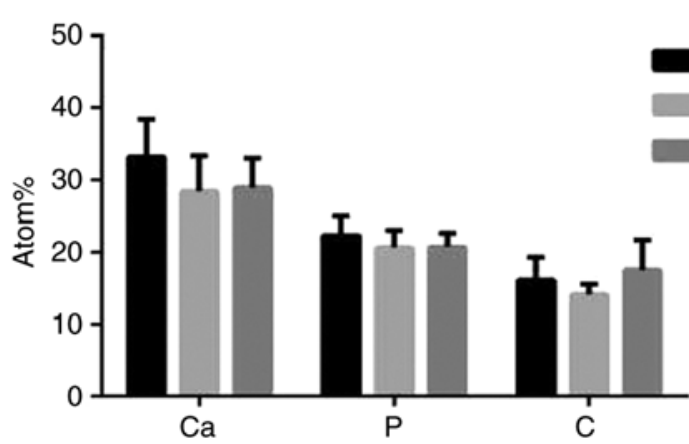

$0 \mathrm{mg} / \mathrm{kg} / \mathrm{day}$

$50 \mathrm{mg} / \mathrm{kg} / \mathrm{day}$

$100 \mathrm{mg} / \mathrm{kg} /$ day

$0 \mathrm{mg} / \mathrm{kg} / \mathrm{day}$

$50 \mathrm{mg} / \mathrm{kg} / \mathrm{day}$

$100 \mathrm{mg} / \mathrm{kg} /$ day

$0 \mathrm{mg} / \mathrm{kg} / \mathrm{day}$

$50 \mathrm{mg} / \mathrm{kg} / \mathrm{day}$

$100 \mathrm{mg} / \mathrm{kg} / \mathrm{day}$

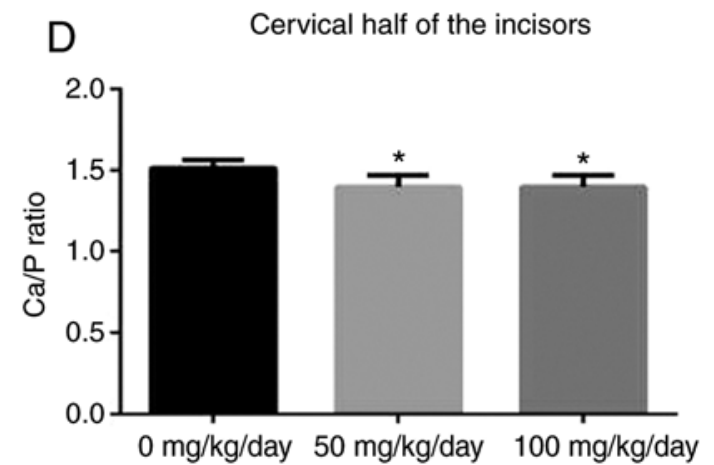

$\mathrm{F}$

$0 \mathrm{mg} / \mathrm{kg} / \mathrm{day}$

$50 \mathrm{mg} / \mathrm{kg} / \mathrm{day}$

$100 \mathrm{mg} / \mathrm{kg} /$ day

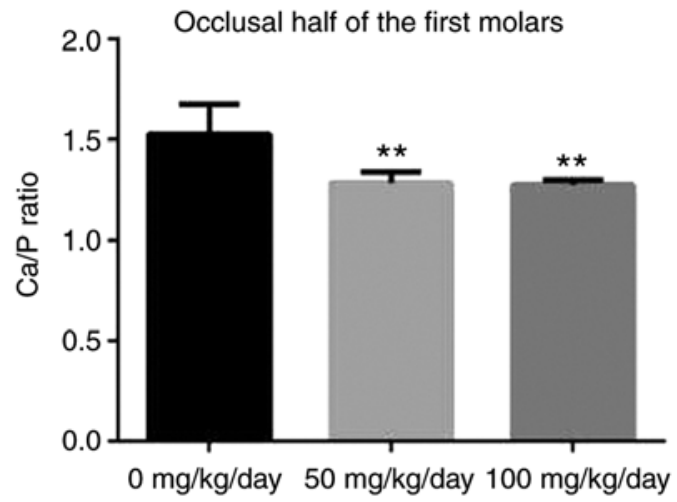

$\mathrm{H}$

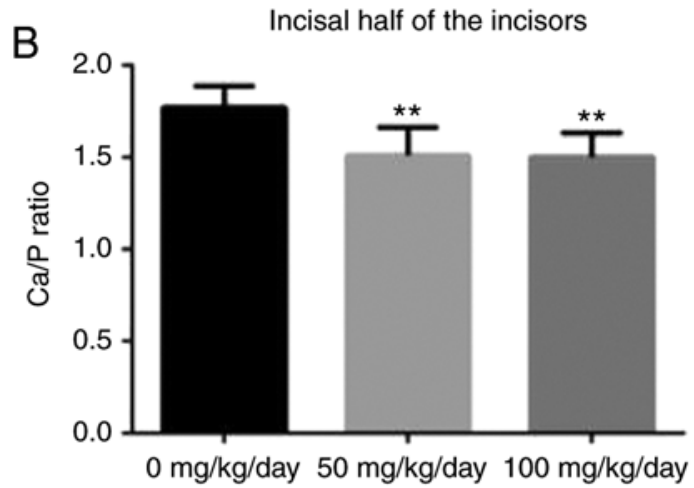

Cervical half of the incisors

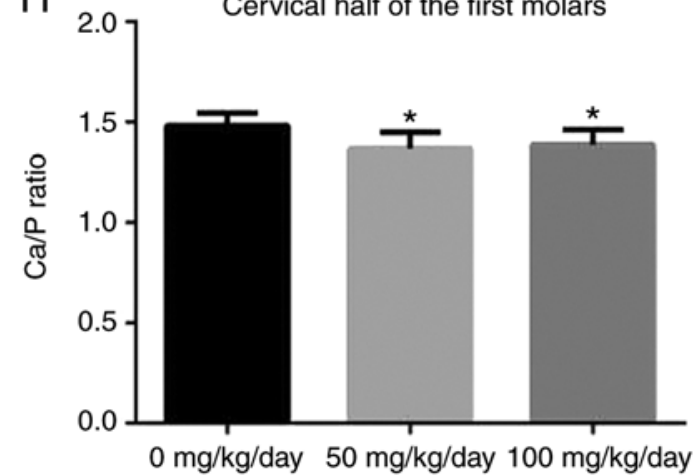

Figure 5. Effects of amoxicillin on enamel $\mathrm{Ca}, \mathrm{P}$ and $\mathrm{C}$ levels and the $\mathrm{Ca} / \mathrm{P}$ ratio of the mandibular incisors and molars, as analyzed by $\mathrm{X}$-ray spectroscopy analysis. Data are presented as mean \pm standard deviation. (A) $\mathrm{Ca}, \mathrm{P}$ and $\mathrm{C}$ atom\% of the enamel surface of the incisors incisal half. (B) The Ca/P ratio of the enamel surface of the incisors incisal half. (C) $\mathrm{Ca}, \mathrm{P}$ and $\mathrm{C}$ atom\% of the enamel surface of the incisors cervical half. (D) The Ca/P ratio of the enamel surface of the incisors cervical half. (E) Ca, $\mathrm{P}$ and $\mathrm{C}$ atom\% of the enamel surface of the first molars occlusal half. (F) The Ca/P ratio of the enamel surface of the occlusal half. (G) Ca, $\mathrm{P}$ and $\mathrm{C}$ atom\% of the enamel surface of the first molars cervical half. $(\mathrm{H}) \mathrm{The} \mathrm{Ca} / \mathrm{P}$ ratio of the enamel surface of the cervical half. ${ }^{*} \mathrm{P}<0.05,{ }^{* *} \mathrm{P}<0.01$ vs. $0 \mathrm{mg} / \mathrm{kg}$ amoxicillin-exposed group. Ca, calcium; $\mathrm{P}$, phosphorous; $\mathrm{C}$, carbon; Atom\%, atom percentage.

mandibular incisors is covered by the maxillary incisors (39). Therefore, during chewing, the incisal/occlusal half of the enamel buccal/labial surface bears a greater friction than the cervical half of enamel (40). This may cause greater enamel defects in the incisal/occlusal half of the enamel surface than in the cervical half of the enamel. Furthermore, when the enamel 


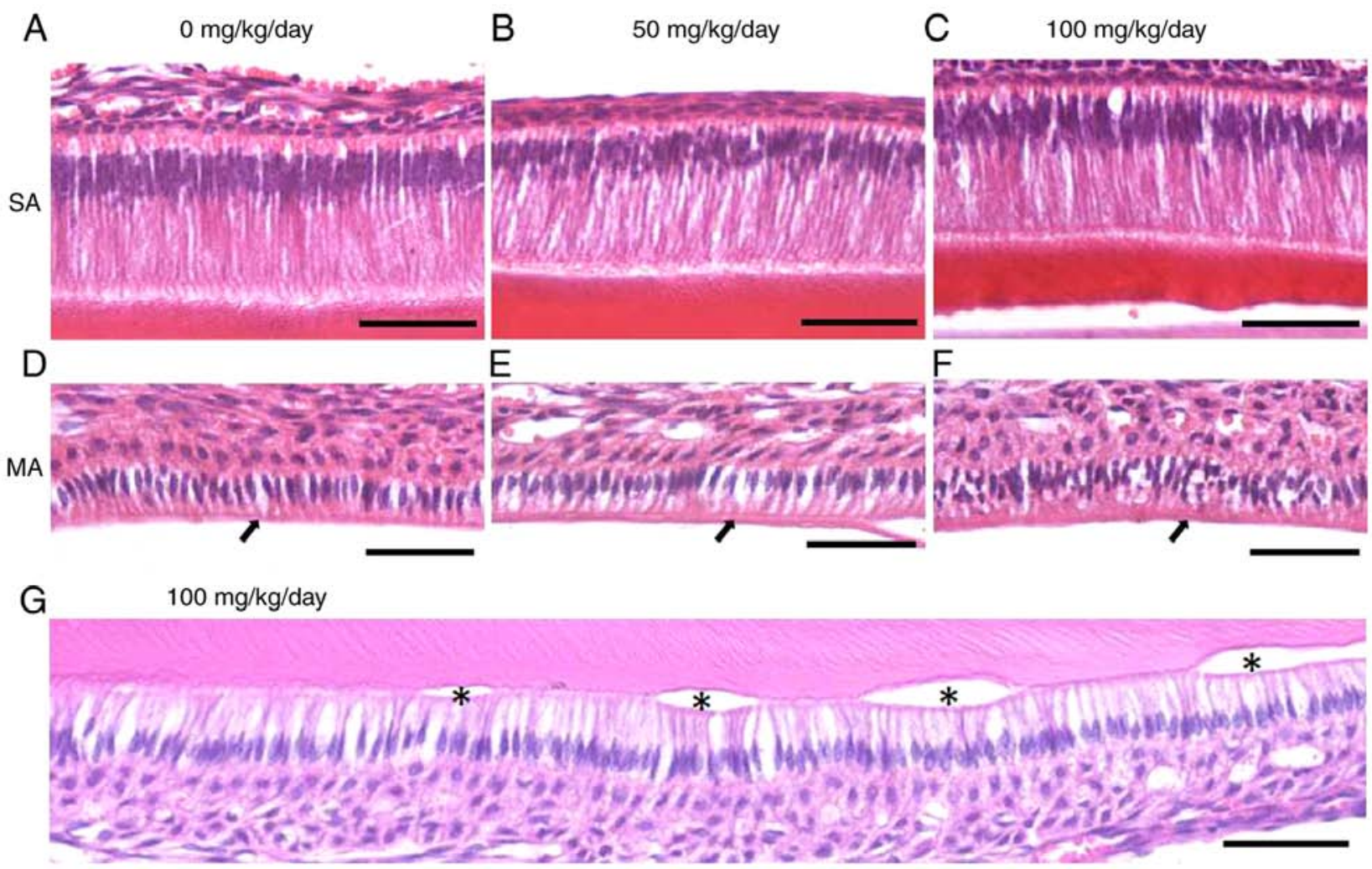

Figure 6. Effects of amoxicillin on the morphology of the secretory and mature ameloblasts, as analyzed by haematoxylin and eosin staining. (A) The morphology of the secretory ameloblasts in the $0 \mathrm{mg} / \mathrm{kg} / \mathrm{day}$ amoxicillin-exposed group. (B) The morphology of the secretory ameloblasts in the $50 \mathrm{mg} / \mathrm{kg} / \mathrm{day}$ amoxicillin-exposed group. (C) The morphology of the secretory ameloblasts in the $100 \mathrm{mg} / \mathrm{kg} / \mathrm{day}$ amoxicillin-exposed group. (D) The morphology of the mature ameloblasts in the $0 \mathrm{mg} / \mathrm{kg} /$ day amoxicillin-exposed group. (E) The morphology of the mature ameloblasts in the $50 \mathrm{mg} / \mathrm{kg} / \mathrm{day}$ amoxicillin-exposed group. (F) The morphology of the mature ameloblasts in the $100 \mathrm{mg} / \mathrm{kg} /$ day amoxicillin-exposed group. (G) Some mature ameloblasts separated from the enamel in the $100 \mathrm{mg} / \mathrm{kg} / \mathrm{day}$ amoxicillin-exposed group. There were larger intercellular spaces (black arrow) between mature ameloblasts in the 50 and $100 \mathrm{mg} / \mathrm{kg} / \mathrm{day}$ amoxicillin-exposed groups. Asterisk indicates cyst-like lesions between the mature ameloblasts and the enamel. SA, serectory ameloblasts; MA, mature ameloblasts. Scale bars, $50 \mu \mathrm{m}$.

is hypomineralized, the mechanical properties of the enamel, such as pressure and friction resistance, are decreased (41-43). Therefore, enamel defects were more obvious in the amoxicillin-exposed groups than in the control group. The enamel defects in the occlusal half of the molars tended to not be as severe as those in the incisal half of the mandibular incisor enamel. This may result from the shorter masticating experience of the mandibular first molar. The first molars of mice often erupt on postnatal day 20 (31). When samples of the mice were collected on postnatal day 25 , the mandibular first molars experience mastication for only 5 days, which is shorter than the mandibular incisors.

The rods and interrod enamel are the fundamental organizational units of mammalian fully maturation enamel (44-45). In the present study, following phosphoric acid etching, the featureless and amorphous appearance of enamel induced by amoxicillin was similar to a SEM study of human enamel opacities (43). The different acid response of enamel between the control and experiment groups suggested that the histological characteristics and mineralization of enamel may be affected by amoxicillin.

It has been reported that amoxicillin interferes with the initial stages of amelogenesis by causing structural changes in ameloblasts (46). However, in the present study, no obvious changes in secretory ameloblasts were found among the groups. Some changes in secretory ameloblasts may have been induced by amoxicillin; however, they were not detected due to the limitation of the examination method used in the present study. The widening intercellular spaces between mature ameloblasts were observed in the amoxicillin-exposed groups, which suggested that amoxicillin affects the connection between mature ameloblasts. Several studies have demonstrated that enamel hypomineralization can be exacerbated by certain potentiating factors, such as amoxicillin and fluoride, bisphenol $\mathrm{A}$ and fluoride $(16,25,27)$. In the present study, similar to the changes induced by an overdose of fluoride $(29,47)$, amoxicillin induced more cyst-like lesions and a decrease in the level of KLK4 in mature ameloblasts, which indicated that amoxicillin may exacerbate dental fluorosis by forming cyst-like lesions and decreasing KLK4 expression.

TJs are widely distributed at the top of all epithelial and endothelial cells (48). Several studies have found that the TJ proteins, CLDN1, CLDN4 and OCLN, are expressed in mature ameloblasts. These proteins may regulate paracellular permeability to create a microenvironment suitable for enamel maturation (9-13). In the present study, amoxicillin reduced CLDN1, CLDN4 and OCLN expression in mature ameloblasts, which indicated that amoxicillin may influence TJs in cells during enamel maturation, thereby defecting the paracellular permeability and microenvironment for enamel mineralization. This may also be associated with the widening intercellular spaces and cyst-like lesions in mature ameloblasts; however, this warrants further investigations. In addition, the decreased KLK4 protein expression induced by amoxicillin 

A
$0 \mathrm{mg} / \mathrm{kg} / \mathrm{day}$
B
$50 \mathrm{mg} / \mathrm{kg} /$ day
C
$100 \mathrm{mg} / \mathrm{kg} /$ day
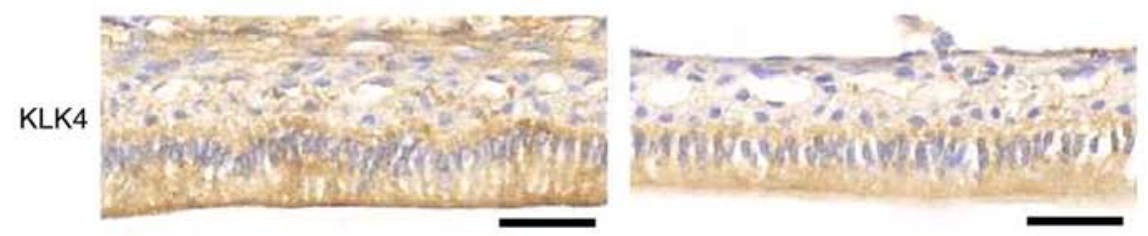

D

E
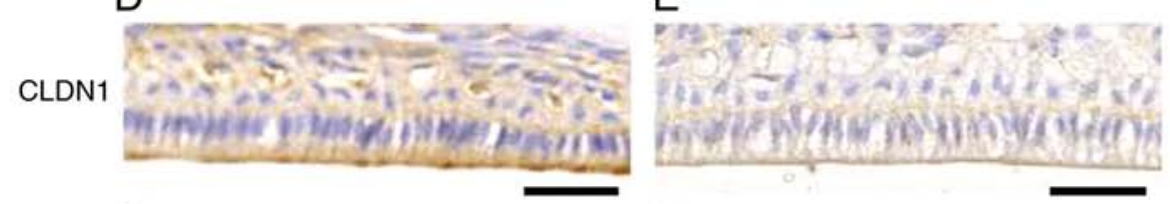

G

$\mathrm{H}$
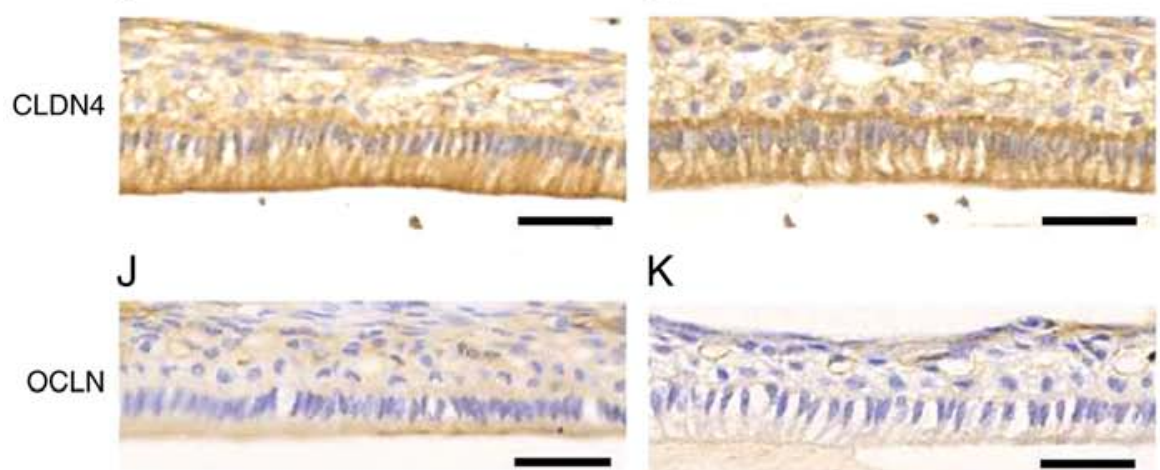

$\mathrm{K}$
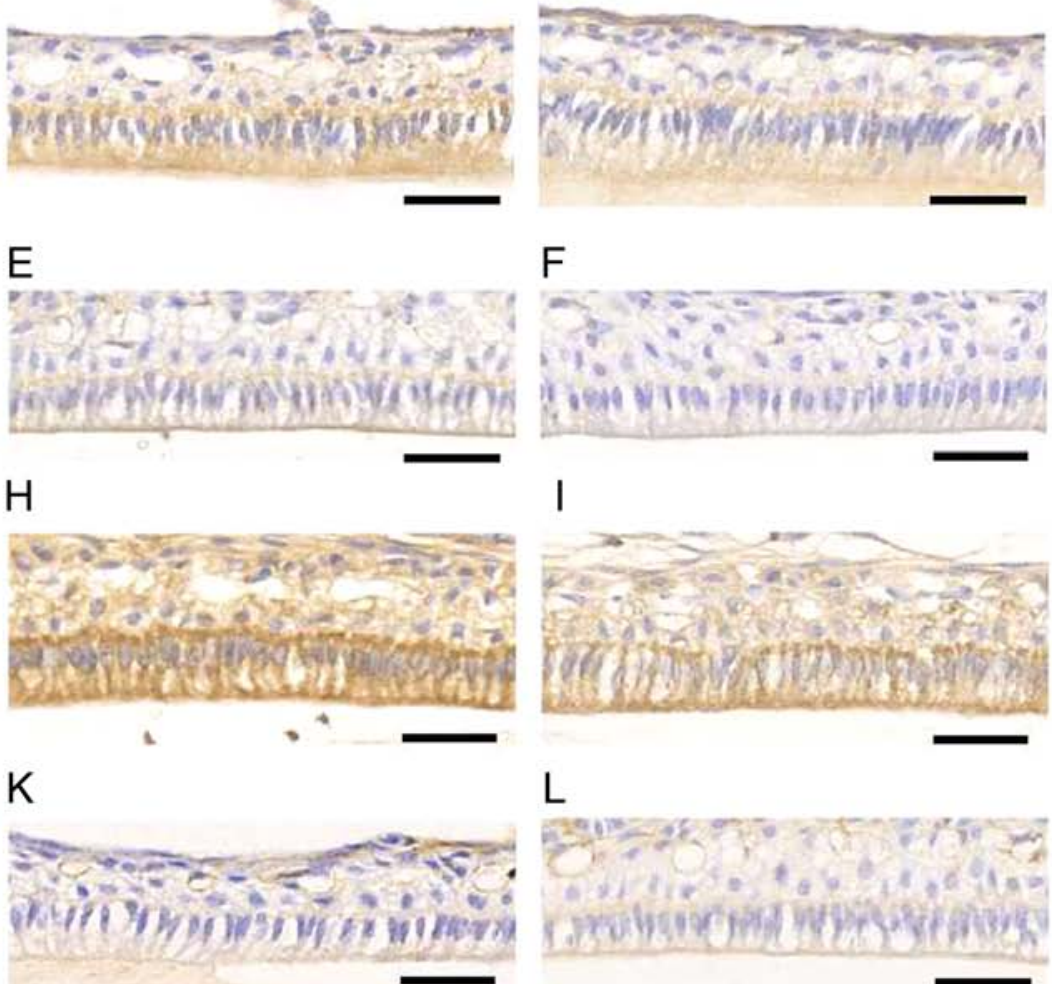

1

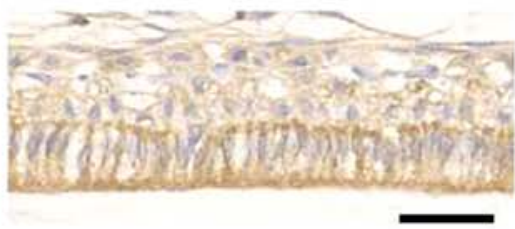

$\mathrm{L}$

M
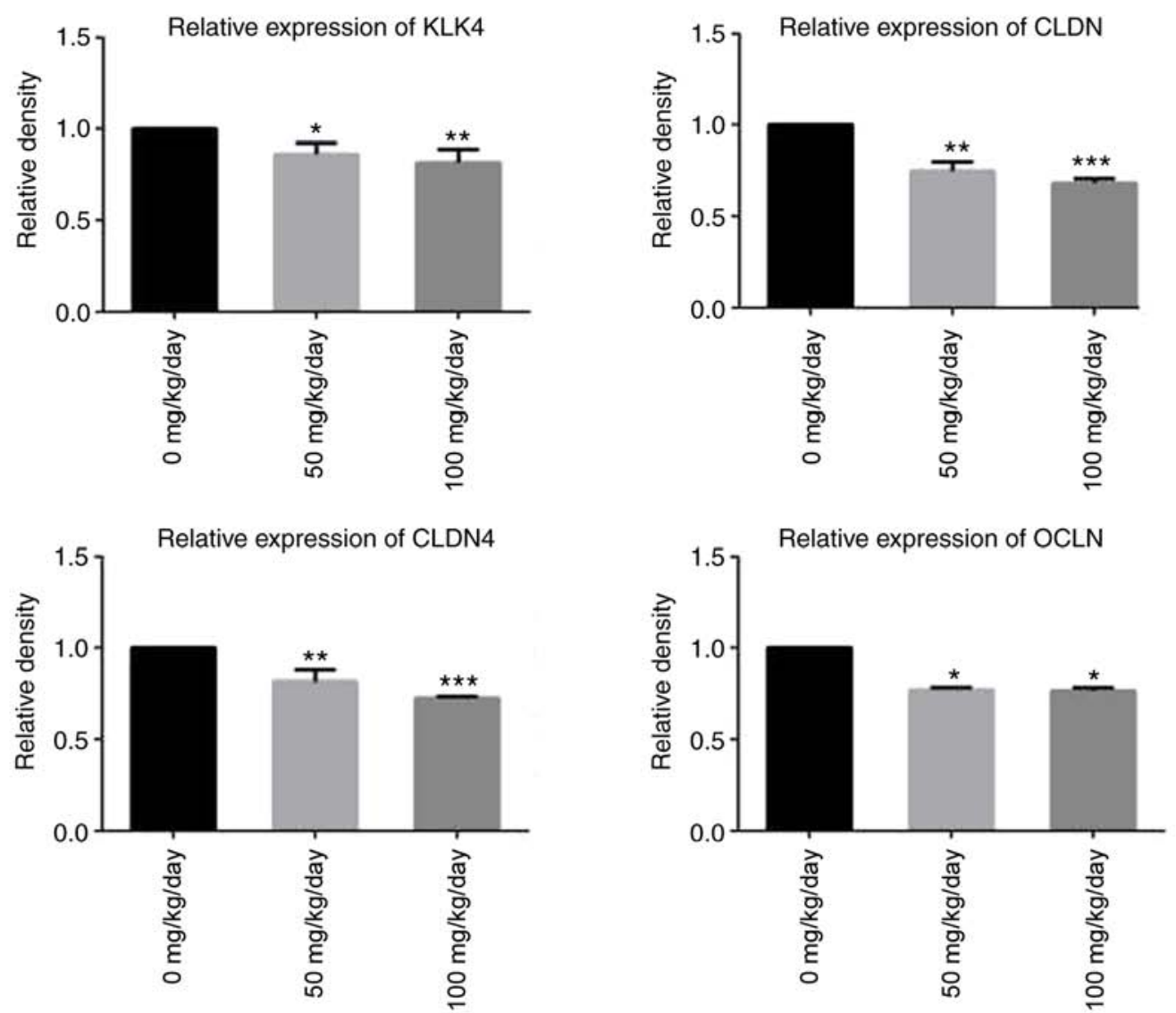

Figure 7. Effects of amoxicillin on the expression of KLK4, CLDN1, CLDN4 and OCLN in mature ameloblasts of the incisors, as analyzed by immunohistochemical staining. The expression of KLK4 in (A) 0 , (B) 50 and (C) $100 \mathrm{mg} / \mathrm{kg} / \mathrm{day}$ amoxicillin-exposed groups. The expression of CLDN1 in (D) 0 , (E) 50 and (F) $100 \mathrm{mg} / \mathrm{kg} /$ day amoxicillin-exposed groups. The expression of CLDN4 in (G) 0 , (H) 50 and (I) $100 \mathrm{mg} / \mathrm{kg} / \mathrm{day}$ amoxicillin-exposed groups. The expression of OLCN in (J) $0,(\mathrm{~K}) 50$ and (L) $100 \mathrm{mg} / \mathrm{kg} / \mathrm{day}$ amoxicillin-exposed groups. Scale bars, $50 \mu \mathrm{m}$. (M) The quantification of immunohistochemical staining of KLK4, CLDN1, CLDN4 and OLCN in mature ameloblasts in the $0,50,100 \mathrm{mg} / \mathrm{kg} /$ day amoxicillin-exposed groups. ${ }^{*} \mathrm{P}<0.05,{ }^{* * *} \mathrm{P}<0.01,{ }^{* * * *} \mathrm{P}<0.001 \mathrm{vs} .0 \mathrm{mg} / \mathrm{kg}$ amoxicillin-exposed group. KLK4, kallikrein-related peptidase 4; CLDN, claudin; OCLN, occludin. 
indicated that the effect of amoxicillin on enamel mineralization may be diverse; however, the key mechanism leading to enamel hypomineralization requires further investigation.

In conclusion, the present study demonstrated that amoxicillin led to enamel hypomineralization in young Kunming mice, and the effect of amoxicillin on hypomineralization may involve multiple pathways. Due to various factors capable of influencing the response in vivo, the results of the present study warrant further investigation in vitro.

\section{Acknowledgements}

Not applicable.

\section{Funding}

This study was supported by National Natural Science Foundation of China (grant no. 81602812), Fundamental Research Funds for Central Universities of China (grant no. xjj2016105), and the Shaanxi Health Family Planning Research Fund (grant no. 2016D016).

\section{Availability of data and materials}

The datasets used and/or analyzed during the current study are available from the corresponding author on reasonable request.

\section{Authors' contributions}

JG, XLi, LG, HC, BHB, XLiu and HL performed experiments. JG, XLi and AR assisted with the experiments, and drafted the article and revised it critically for important intellectual content. MG and JR designed the study, oversaw the experiments and provided overall guidance and interpretation of the results. All authors read and approved the final manuscript.

\section{Ethics approval and consent to participate}

All experimental protocols were approved by the Ethics Committee for the Use of Human or Animal Subjects of Xi'an Jiaotong University (Xi'an, China).

\section{Patient consent for publication}

Not applicable.

\section{Competing interests}

The authors declare that they have no competing interests.

\section{References}

1. Lacruz RS, Habelitz S, Wright JT and Paine ML: Dental enamel formation and implications for oral health and disease. Physiol Rev 97: 939-993, 2017

2. Frank RM and Nalbandian J: Ultrastructure of amelogenesis. In: Structural and Chemical Organization of Teeth. Miles AEW (ed). Vol. 1 Academic Press, New York, pp399-466, 1967.

3. Robinson C, Kirkham J, Brookes SJ, Bonass WA and Shore RC: The chemistry of enamel development. Int J Dev Biol 39: $145-152,2003$
4. Schmitz JE, Teepe JD, Hu Y, Smith CE, Fajardo RJ and Chun YH: Estimating mineral changes in enamel formation by ashing/BSE and microCT. J Dent Res 93: 256-262, 2014.

5. Bardet C, Ribes S, Wu Y, Diallo MT, Salmon B, Breiderhoff T, Houillier P, Müller D and Chaussain C: Claudin loss-of-function disrupts tight junctions and impairs amelogenesis. Front Physiol 8: 326, 2017.

6. Anderson JM and Van Itallie CM: Tight junctions and the molecular basis for regulation of paracellular permeability. Am J Physiol 269: G467-G475, 1995.

7. Ma TY, Nighot P and Al-Sadi R: Tight junctions and the intestinal barrier. In: Physiology of the Gastrointestinal Tract. Vol 1-2. 6th edition. Elsevier, Inc., pp587-639, 2018.

8. Lumsden AG: Spatial organization of the epithelium and the role of neural crest cells in the initiation of the mammalian tooth germ. Development 103(Suppl): 155-169, 1988.

9. Hata M, Kawamoto T, Kawai M and Yamamoto T: Differential expression patterns of the tight junction-associated proteins occludin and claudins in secretory and mature ameloblasts in mouse incisor. Med Mol Morphol 43: 102-106, 2010.

10. Suzuki H, Tani K, Tamura A, Tsukita S and Fujiyoshi Y: Model for the architecture of claudin-based paracellular ion channels through tight junctions. J Mol Biol 427: 291-297, 2015.

11. Kirschner N, Rosenthal R, Furuse M, Moll I, Fromm M and Brandner JM: Contribution of tight junction proteins to ion, macromolecule, and water barrier in keratinocytes. J Invest Dermatol 133: 1161-1169, 2013.

12. Elmadih A, Wan MW, Downey D, Elliott R, Swain JE and Abel KM: Natural variation in maternal sensitivity is reflected in maternal brain responses to infant stimuli. Behav Neurosci 130: 500-510, 2016

13. Inai T, Sengoku A, Hirose E, Iida $H$ and Shibata Y: Differential expression of the tight junction proteins, claudin-1, claudin-4, occludin, ZO-1, and PAR3, in the ameloblasts of rat upper incisors. Anat Rec (Hoboken) 291: 577-585, 2008.

14. Jeremias F, Koruyucu M, Küchler EC, Bayram M, Tuna EB, Deeley K, Pierri RA, Souza JF, Fragelli CM, Paschoal MA, et al: Genes expressed in dental enamel development are associated with molar-incisor hypomineralization. Arch Oral Biol 58: 1434-1442, 2013.

15. Jeremias F, Pierri RA, Souza JF, Fragelli CMB, Restrepo M, Finoti LS, Bussaneli DG, Cordeiro RC, Secolin R, Maurer-Morelli CV, et al: Family-based genetic association for molar-incisor hypomineralization. Caries Res 50: 310-318, 2016.

16. Jedeon K, Houari S, Loiodice S, Thuy TT, Le Normand M, Berdal A and Babajko S: Chronic exposure to bisphenol A exacerbates dental fluorosis in growing rats. J Bone Miner Res 31: 1955-1966, 2016.

17. Hubbard MJ, Mangum JE, Perez VA, Nervo GJ and Hall RK: Molar hypomineralisation: A call to arms for enamel researchers. Front Physiol 8: 546, 2017.

18. Jeremias F, de Souza JF, Silva CM, Cordeiro Rde C, Zuanon AC and Santos-Pinto L: Dental caries experience and molar-incisor hypomineralization. Acta Odontol Scand 71: 870-876, 2013.

19. Mast P, Rodrigueztapia MT, Daeniker L and Krejci I: Understanding MIH: Definition, epidemiology, differential diagnosis and new treatment guidelines. Eur J Paediatr Dent 14: 204-208, 2013.

20. Mill C, Primeau MN, Medoff E, Lejtenyi C, O'Keefe A, Netchiporouk E, Dery A and Ben-Shoshan M: Assessing the diagnostic properties of a graded oral provocation challenge for the diagnosis of immediate and nonimmediate reactions to amoxicillin in children. JAMA Pediatr 170: e160033, 2016.

21. Weerheijm KL: Molar incisor hypomineralization (MIH): Clinical presentation, aetiology and management. Dent Update 31: 9-12, 2004.

22. Laisi S, Ess A, Sahlberg C, Arvio P, Lukinmaa PL and Alaluusua S: Amoxicillin may cause molar incisor hypomineralization. J Dent Res 88: 132-136, 2009.

23. Wuollet E, Laisi S, Salmela E, Ess A and Alaluusua S: Molarincisor hypomineralization and the association with childhood illnesses and antibiotics in a group of Finnish children. Acta Odontol Scand 74: 416-422, 2016.

24. Gottberg B, Berné J, Quiñónez B and Solórzano E: Prenatal effects by exposing to amoxicillin on dental enamel in Wistar rats. Med Oral Patol Oral Cir Bucal 19: e38-e43, 2014.

25. Hong L, Levy SM, Warren JJ, Bergus GR, Dawson DV, Wefel JS and Broffitt B: Primary tooth fluorosis and amoxicillin use during infancy. J Public Health Dent 64: 38-44, 2004. 
26. Hong L, Levy SM, Warren JJ and Broffitt B: Amoxicillin use during early childhood and fluorosis of later developing tooth zones. J Public Health Dent 71: 229-235, 2011.

27. Sahlberg C, Pavlic A, Ess A, Lukinmaa PL, Salmela E and Alaluusua S: Combined effect of amoxicillin and sodium fluoride on the structure of developing mouse enamel in vitro. Arch Oral Biol 58: 1155-1164, 2013.

28. Li X, Xu G, Qiao T, Yuan S and Zhuang X: Effects of CpG oligodeoxynucleotide 1826 on acute radiation-induced lung injury in mice. Biol Res 49: 8, 2016.

29. Gao J, Ruan J and Gao L: Excessive fluoride reduces Foxo1 expression in dental epithelial cells of the rat incisor. Eur J Oral Sci 122: 317-323, 2014.

30. Gu J, Liang Y, Qiao L, Li X, Li X, Lu Y and Zheng Q: Expression analysis of URI/RMP gene in endometrioid adenocarcinoma by tissue microarray immunohistochemistry. Int J Clin Exp Pathol 6: 2396-2403, 2013.

31. Gao Y, Wang W, Sun Y, Zhang J, Li D, Wei Y and Han T: Distribution of amelotin in mouse tooth development. Anat Rec (Hoboken) 293: 135-140, 2010

32. Jeske AH: Mosby's Dental Drug Reference. 12th edition. Elsevier, Inc., St. Louis, Mo., 2018.

33. Lexicomp Online, Pediatric and Neonatal Lexi-Drugs Online. Wolters Kluver Clinical Drug Information. https://www.wolterskluwercdi.com/drug-data/drug-screening/

34. Dept. of Health and Human Services, Food and Drug Administration, Center for Drug Evaluation and Research: Guidance for industry estimating the maximum safe starting dose in initial clinical trials for therapeutics in adult healthy. Rockville, MD, 2005.

35. Mihalaş E, Matricala L, Chelmuş A, Gheţu N,Petcu A and Paşca S: The role of chronic exposure to amoxicillin/clavulanic acid on the developmental enamel defects in mice. Toxicol Pathol 44: 61-70, 2016.

36. Villarroel M, Fahl N, De Sousa AM and De Oliveira OB Jr: Direct esthetic restorations based on translucency and opacity of composite resins. J Esthet Restor Dent 23: 73-87, 2011.

37. Winter R: Visualizing the natural dentition. J Esthet Dent 5 : $103-118,1993$

38. Møinichen CB, Lyngstadaas SP and Risnes S: Morphological characteristics of mouse incisor enamel. J Anat 189(Pt 2): 325-333, 1996.
39. Davies S and Gray RM: What is occlusion? Br Dent J 191: 235-245, 2001.

40. d'Incau E, Couture C and Maureille B: Human tooth wear in the past and the present: Tribological mechanisms, scoring systems, dental and skeletal compensations. Arch Oral Biol 57: 214-229, 2012.

41. Mahoney E, Ismail FS, Kilpatrick N and Swain M: Mechanical properties across hypomineralized/hypoplastic enamel of first permanent molar teeth. Eur J Oral Sci 112: 497-502, 2004.

42. Mahoney EK, Rohanizadeh R, Ismail FS, Kilpatrick NM and Swain MV: Mechanical properties and microstructure of hypomineralised enamel of permanent teeth. Biomaterials 25: 5091-5100, 2004.

43. Fagrell TG, Dietz W, Jälevik B and Norén JG: Chemical, mechanical and morphological properties of hypomineralized enamel of permanent first molars. Acta Odontol Scand 68: 215-222, 2010

44. Nanci A and Smith CE: Development and calcification of enamel. Calcification in biological systems 313-343: 1992.

45. Weiner S: Organization of extracellularly mineralized tissues: A comparative study of biological crystal growt. CRC Crit Rev Biochem 20: 365-408, 1986.

46. de Souza JF, Gramasco M, Jeremias F, Santos-Pinto L, Giovanini AF, Cerri PS and Cordeiro Rde C: Amoxicillin diminishes the thickness of the enamel matrix that is deposited during the secretory stage in rats. Int J Paediatr Dent 26: 199-210, 2016

47. Bronckers AL, Lyaruu DM and DenBesten PK: The impact of fluoride on ameloblasts and the mechanisms of enamel fluorosis. J Dent Res 88: 877-893, 2009.

48. Zihni C, Mills C, Matter K and Balda MS: Tight junctions: From simple barriers to multifunctional molecular gates. Nat Rev Mol Cell Biol 17: 564-580, 2016.

This work is licensed under a Creative Commons Attribution-NonCommercial-NoDerivatives 4.0 International (CC BY-NC-ND 4.0) License. 